\title{
Color Space to Detect Skin Image: The Procedure and Implication
}

\author{
Sukmawati Nur Endah ${ }^{1}$, Retno Kusumaningrum², Helmie Arif Wibawa ${ }^{3}$ \\ ${ }^{1,2,3}$ Computer Science Department, Universitas Diponegoro, Indonesia \\ E-mail: ${ }^{1}$ sukma_ne@ undip.ac.id, ${ }^{2}$ retno@live.undip.ac.id, ${ }^{3}$ helmie.arif@if.undip.ac.id
}

\begin{abstract}
Skin detection is one of the processes to detect the presence of pornographic elements in an image. The most suitable feature for skin detection is the color feature. To be able to represent the skin color properly, it is needed to be processed in the appropriate color space. This study examines some color spaces to determine the most appropriate color space in detecting skin color. The color spaces in this case are RGB, HSV, HSL, YIQ, YUV, YCbCr, YPbPr, YDbDr, CIE XYZ, CIE L*a*b*, CIE L*a* $\mathrm{v}^{*}$, and CIE L*ch. Based on the test results using 400 image data consisting of 200 skin images and 200 non-skin images, it is obtained that the most appropriate color space to detect the color is CIE L*u*v*.
\end{abstract}

Keywords: Skin Detection, Color Feature, Color Space Coversion

\section{INTRODUCTION}

Skin is a part of human body. In an image, skin is able to present the existence of human. Furthermore, it can also be determined how many the skin is exposed in an image. The more skin is exposed, the more naked the human object in the image. In further process, it may indicate the presence of pornographic elements in the image.

In skin detection process, the most suitable feature is the color feature, if compared to others. Talking about color feature, it is exactly related to the color space and its descriptors. Color feature extraction in the appropriate color space will impact on the accuracy of the detection [1]. Take the research done by Vasthi dan Kusumaningrum as an example,stating that the color space for fruits object is more suitable using the OHTA color space [2]. For skin object, from the research by Isa dan Mariana, it is stated that RGB color space, commonly used for system input, has perceptually congruent characteristics, meaning that the RGB characteristic cannot depict the system sensitivity of human sight and thus RGB model is not quite suitable to detect skin color [3]. On the other hand, in the research of Zhuo et. al., YCbCr color model was used to perform skin detection because the distribution of all skin colors and races is more concentrated in $\mathrm{YCbCr}$ color space, if compared to others [4]. However, the two researches did not compare the used color space with others. Hence, this research will examine the most appropriate color space for skin object by comparing some color spaces available. 
Descriptors for color spaces are, such as pixel, color histogram, and color moment. If the descriptor is a value of pixel, then the dimensionality will be valued high. Meanwhile for histogram and color moment, a research by Stricker dan Orengo has proven that color moment yields better result than the color histogram does [5]. Hence, this research will compare some color spaces with color moment as the descriptor.

\section{METHODS}

The next stages conducted in this research can be seen in process blocks in Figure 1.

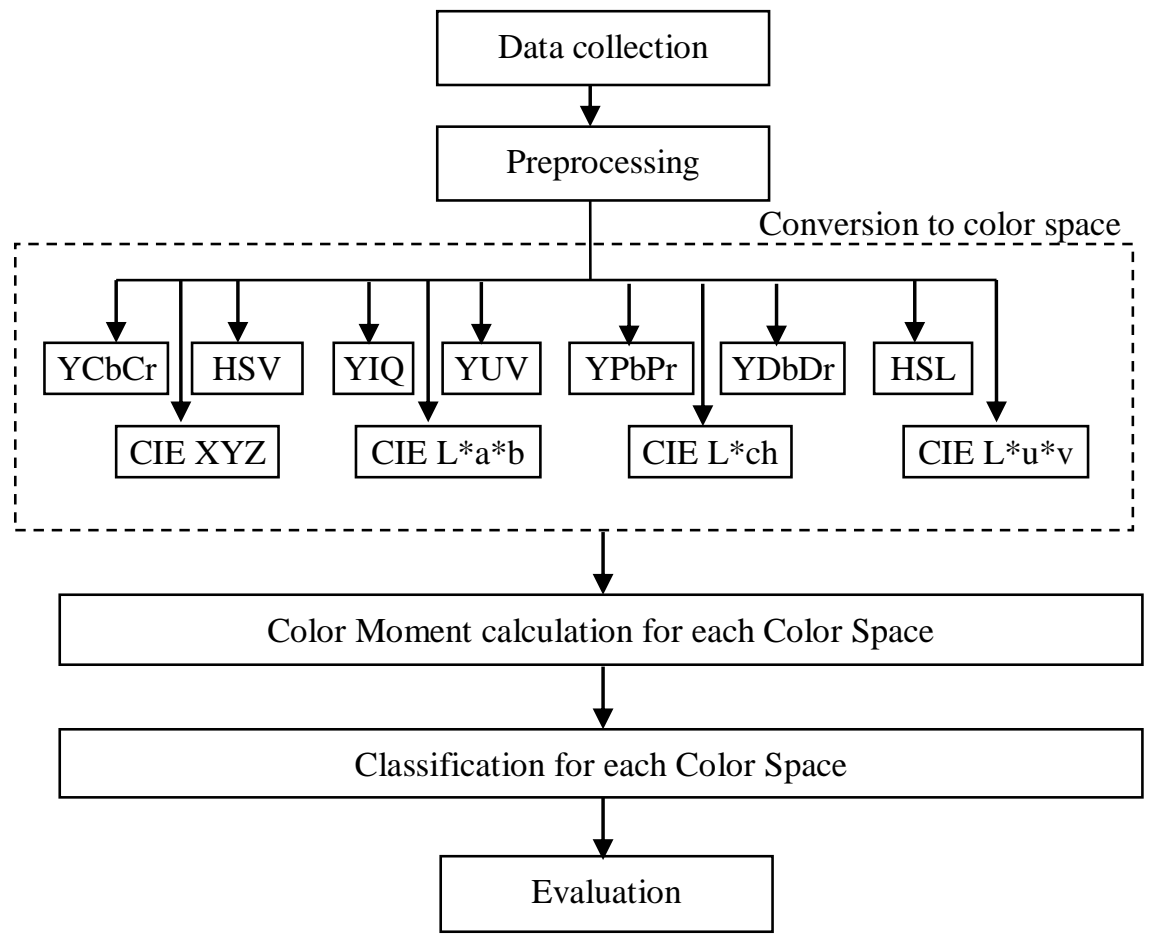

Figure 1. Process blocks of research plot alur penelitian

Details of the stages can be explained as follows.

a. Data collection

Data that were collected are the image data containing human skin (naked man image and naked woman image), and non-skin image containing the same color as skin color, such as man in brown clothes and whitish brown house. For skin image, image sample is taken to represent all races existing on earth. The races are as follows:

1) Mongoloid

Consisting: Asiatic Mongoloid (North Asia, Central Asia, dan East Asia), Malayan Mongoloid (Middle East Asia, Indonesia, Malaysia, Philippines, 
and Taiwannative inhabitants), and American Mongoloid (American native inhabitants)

2) Negroid

Consisting: African Negroid (Africa), Negrito (Central Africa, Malay Peninsula known as Semang and Philippines inhabitants), and Melanesian (Papua dan Melanesia)

3) Caucasoid

Consisting: Nordic (North Europe, around Baltic Sea), Alpine (Central Europe and East Europe), Mediterranean (around Mediterranean, North Africa, Armenia, Arab, and Iran), and Indic (Pakistan, India, Bangladesh, and Sri Lanka)

Each race image collected also consists of images of male and female. The collected images are RGB images.

b. Preprocessing

Preprocessing here is resizing the initial image size into image in 64 x 64 pixels.

c. Conversion to color space

Input image of RGB image will be converted to different color spaces. The 12 color spaces that will be examined in this research including the RGB color space. The color spaces, i.e.: RGB, HSV, HSL, YIQ, YUV, YCbCr, YPbPr, YDbDr, CIE XYZ, CIE L*a*b*, CIE L*u*v*, and CIE L*ch.

To do the conversion from RGB color space to color spaces above, the following formula is used:

1) Conversion from RGB to HSV

This conversion will alter the $\mathrm{R}, \mathrm{G}, \mathrm{B}$ values, initially at $0 . .255$ range to $0 . .1$ range. The formula used is as follows [6]:

$$
\begin{aligned}
& R^{\prime}=R / 255 \\
& G^{\prime}=G / 255 \\
& B^{\prime}=B / 255 \\
& C \max =\max \left(R^{\prime}, G^{\prime}, B^{\prime}\right) \\
& C \min =\min \left(R^{\prime}, G^{\prime}, B^{\prime}\right) \\
& \Delta=C \max -C \min
\end{aligned}
$$

H (Hue) calculation:

$$
H=\left\{\begin{array}{cc}
0^{\circ} & \Delta=0 \\
60^{\circ} \times\left(\frac{G^{\prime}-B^{\prime}}{\Delta} \bmod 6\right) & , C_{\max }=R^{\prime} \\
60^{\circ} \times\left(\frac{B^{\prime}-R^{\prime}}{\Delta}+2\right) & , C_{\max }=G^{\prime} \\
60^{\circ} \times\left(\frac{R^{\prime}-G^{\prime}}{\Delta}+4\right) & , C_{\max }=B^{\prime}
\end{array}\right.
$$

S (Saturation) calculation:

$$
S=\left\{\begin{array}{cc}
0 & , C_{\max }=0 \\
\frac{\Delta}{C_{\max }} & , C_{\max } \neq 0
\end{array}\right.
$$

$\mathrm{V}$ (Value) calculation:

$$
V=C \max
$$


2) Conversion from RGB to HSL

To convert RGB to HSL (Hue, Saturation, Lightness), equation (1) to equation (6) are still relevant. Hue calculation uses equation (7), while saturation and lightness calculation are as follows:

$\mathrm{S}$ (Saturation) calculation:

$$
S=\left\{\begin{array}{c}
0, C_{\max }+C_{\min }=2 \\
\frac{\Delta}{1-\left|C_{\max }+C_{\min }-1\right|}, C_{\max }+C_{\min } \neq 2
\end{array}\right.
$$

L (Lightness) calculation:

$$
L=1 / 2(C \max +C \min )
$$

3) Conversion from RGB to YIQ

The conversion from RGB to YIQ uses the formula as follows [7]:

$$
\begin{aligned}
& \mathrm{Y}=0.299 * \mathrm{R}+0.587 * \mathrm{G}+0.114 * \mathrm{~B} \\
& \mathrm{I}=0.596 * \mathrm{R}-0.275 * \mathrm{G}-0.321 * \mathrm{~B} \\
& \mathrm{Q}=0.212 * \mathrm{R}-0.523 * \mathrm{G}+0.311 * \mathrm{~B}
\end{aligned}
$$

4) Conversion from RGB to YUV

The conversion from RGB to YUVuses the formula as follows [8]:

$$
\begin{aligned}
& \mathrm{Y}=0.299 * \mathrm{R}+0.587 * \mathrm{G}+0.114 * \mathrm{~B} \\
& \mathrm{U}=-0.147 * \mathrm{R}-0.289 * \mathrm{G}+0.436 * \mathrm{~B} \\
& \mathrm{~V}=0.615 * \mathrm{R}-0.515^{*} \mathrm{G}-0.100 * \mathrm{~B}
\end{aligned}
$$

5) Conversion from $\mathrm{RGB}$ to $\mathrm{YCbCr}$

The conversion from RGB to YCbCruses the formula as follows [8]:

$$
\begin{array}{ll}
\mathrm{Y} & =0.299 * \mathrm{R}+0.587 * \mathrm{G}+0.114 * \mathrm{~B} \\
\mathrm{Cb} & =128+(-0.169 * \mathrm{R}-0.331 * \mathrm{G}+0.500 * \mathrm{~B}) \\
\mathrm{Cr} & =128+(0.500 * \mathrm{R}-0.419 * \mathrm{G}-0.081 * \mathrm{~B})
\end{array}
$$

6) Conversion from RGB toYPbPr

Conversion from RGB to $\mathrm{YPbPr}$ uses the formula as follows [8]:

$$
\begin{aligned}
& \mathrm{Y}=0.213 * \mathrm{R}+0.715^{*} \mathrm{G}+0.072 * \mathrm{~B} \\
& \mathrm{~Pb}=-0.115 * \mathrm{R}-0.385 * \mathrm{G}+0.500 * \mathrm{~B} \\
& \mathrm{Pr}=0.500 * \mathrm{R}-0.454 * \mathrm{G}-0.046 * \mathrm{~B}
\end{aligned}
$$

7) Conversion from RGB toYDbDr

Conversion from RGB to YDbDr uses the formula as follows [9]:

$$
\begin{aligned}
& \mathrm{Y}=0.299 * \mathrm{R}+0.587 * \mathrm{G}+0.114 * \mathrm{~B} \\
& \mathrm{Db}=-0.45 * \mathrm{R}-0.883 * \mathrm{G}+1.333 * \mathrm{~B} \\
& \mathrm{Dr}=-1.333^{*} \mathrm{R}+1.116^{*} \mathrm{G}+0.217^{*} \mathrm{~B}
\end{aligned}
$$

8) Conversion RGB to CIE

To do conversion from RGB to CIE, be it CIE XYZ, CIE L*a*b*, CIE $\mathrm{L}^{*} \mathrm{u}^{*} \mathrm{v}^{*}$, or CIE $\mathrm{L}^{*} \mathrm{ch}$, data have to converted first from RGB to XYZ color space. The conversion procedure refers to equation [10]. 
d. Color Moment calculation

Image that has been resized to $64 \times 64$ is then being taken the sub-image in $5 \times 5$. From the sub-image, the calculation of color moment is later performed in subimage pixel i.e. mean, standard deviation andskewness (gradient). Later, this subimage moves overlapping at each line and column.

e. Classification

Classification is performed by using the Support Vector Machine (SVM) method, with its Kernel is Radial Basis Function (RBF) [11].

f. Evaluation

Evaluation is performed using 10 -fold cross validationto determine the accuracy of each color space.

\section{RESULTS AND DISCUSSION}

\subsection{Result}

The data used in this research are 400 images consisting of 200 images of human skin (100 naked man images, 100 naked woman images) dan 200 non-skin images(100 landscape images such as house, animal images, etc., and 100 images of man wearing skin color-like clothes). The skin images in this case represent all races existing on earth, i.e. Asiatic Mongoloid, Malayan Mongoloid, American Mongoloid, African Negroid, Negrito, Melanesian, Nordic, Alpine, Mediterranean, and Indic. Each race is being represented by 10 images for each sex.

The test uses $\mathrm{K}$-fold cross validation with $\mathrm{k}=10.400$ data are divided into 10 fold, thus the amount of training data are 360 and testing data are 40, consisting of 10 man's skin images, 10 woman's skin images, 10 landscape images, 10 images of man wearing clothes. Table 1 shows the experiment result.

Table 1. Experiment result of each color space

\begin{tabular}{|c|c|c|c|c|c|c|c|c|c|c|c|}
\hline Color Space & $\begin{array}{l}\text { Fold } \\
\mathbf{1}(\%) \\
\end{array}$ & $\begin{array}{l}\text { Fold } \\
2(\%) \\
\end{array}$ & $\begin{array}{l}\text { Fold } \\
\mathbf{3}(\%) \\
\end{array}$ & $\begin{array}{l}\text { Fold } \\
4(\%) \\
\end{array}$ & $\begin{array}{l}\text { Fold } \\
\mathbf{5 ( \% )} \\
\end{array}$ & $\begin{array}{l}\text { Fold } \\
6(\%) \\
\end{array}$ & $\begin{array}{c}\text { Fold } \\
7(\%) \\
\end{array}$ & $\begin{array}{l}\text { Fold } \\
8(\%) \\
\end{array}$ & $\begin{array}{l}\text { Fold } \\
9(\%) \\
\end{array}$ & $\begin{array}{c}\text { Fold } \\
10(\%)\end{array}$ & Avera-ge \\
\hline RGB & 80 & 77,5 & 87,5 & 72,5 & 80 & 80 & 85 & 72,5 & 80 & 85 & 80 \\
\hline HSV & 90 & 92,5 & 90 & 82,5 & 87,5 & 85 & 90 & 87,5 & 85 & 82,5 & 87,25 \\
\hline HSL & 75 & 80 & 87,5 & 95 & 90 & 87,5 & 82,5 & 80 & 87,5 & 82,5 & 84,75 \\
\hline YIQ & 90 & 87,5 & 95 & 92,5 & 95 & 82,5 & 80 & 90 & 92,5 & 92,5 & 89,75 \\
\hline YUV & 87,5 & 85 & 95 & 92,5 & 95 & 82,5 & 92,5 & 92,5 & 90 & 92,5 & 90,5 \\
\hline $\mathrm{YCbCr}$ & 92,5 & 85 & 95 & 90 & 100 & 82,5 & 92,5 & 92,5 & 92,5 & 95 & 91,75 \\
\hline $\mathrm{YPbPr}$ & 87,5 & 82,5 & 95 & 92,5 & 92,5 & 82,5 & 87,5 & 92,5 & 87,5 & 92,5 & 89,25 \\
\hline YDbDr & 87,5 & 82,5 & 95 & 92,5 & 95 & 77,5 & 92,5 & 92,5 & 87,5 & 92,5 & 89,5 \\
\hline CIE XYZ & 75 & 77,5 & 77,5 & 75 & 65 & 70 & 80 & 90 & 87,5 & 72,5 & 77 \\
\hline CIE L*a*b* & 87,5 & 95 & 92,5 & 92,5 & 97,5 & 75 & 95 & 90 & 92,5 & 97,5 & 91,5 \\
\hline CIE L*u*v* & 85 & 95 & 90 & 95 & 95 & 87,5 & 97,5 & 95 & 90 & 95 & 92,5 \\
\hline CIE L*ch & 77,5 & 87,5 & 85 & 80 & 92,5 & 87,5 & 92,5 & 87,5 & 85 & 87,5 & 86,25 \\
\hline
\end{tabular}


Based on Table 1, it can be seen that the color space yields the highest accuracy value in skin detection is CIE $\mathrm{L}^{*} \mathrm{u}^{*} \mathrm{v}^{*}$.

\subsection{Discussion}

High accuracy performed by CIE $\mathrm{L}^{*} \mathrm{u} * \mathrm{v}$ of $92,5 \%$ shows that skin color can be represented better in CIE $\mathrm{L}^{*} \mathrm{u}^{*} \mathrm{v}$ color space. Although some are acting as the non-skin images taken from images with akin colors of that of skins, the images between skin and non-skin show no difference in CIE $\mathrm{L}^{*} \mathrm{u}^{*} \mathrm{v}$ color space.

On the other hand, the highest accuracy yielded without CIE is that of YCbCr of 91 , $75 \%$. It shows that the distribution of all races and skin colors is more concentrated in $\mathrm{YCbCr}$ space, if compared to other spaces other than those of CIE.Hence, for further development of skin detection, the suggested color space is CIE $\mathrm{L}^{*} \mathrm{u}^{*}$ vorYCbCr.

\section{CONCLUSION}

Detecting skin colors, the color space able to produce the highest accuracy rate is CIE $\mathrm{L}^{*} \mathrm{u}^{*} \mathrm{v}$ of $92,5 \%$. If it is not in CIE color space, the highest accuracy rate is $91,75 \%$ of $\mathrm{YCbCr}$ color space.

\section{REFERENCES}

[1] Asmare, M.H., Asirvadam, W.S, Iznito, L. 2009. Color Space Selection for Color Image Enhancement Applications. Proceeding of International Conference on Signal Acquisition and Processing (ICSAP) 2009. KualaLumpur, Malaysia, 3-5 April 2009

[2] Vasthi, P. I., \& Kusumaningrum, R. 2015. Object segmentation for fruit images using OHTA colour space and cascade threshold. In Science in Information Technology (ICSITech), 2015 International Conference on (pp. 321-325). IEEE.

[3] Isa, S.M., Mariana, F. 2009.Deteksi Citra Pornografi Menggunakan TSL Color Space dan Nudity Detection Algorithm. Prosiding. Seminar Nasional Informatika 2009 UPN Veteran Yogyakarta. Yogyakarta, Indonesia, 23 Mei 2009

[4] Zhuo, L., Geng, Z., Zhang, J., \& guang Li, X. 2016. ORB feature based web pornographic image recognition. Neurocomputing, 173(3), 511-517.

[5] Stricker, M., Orengo, M. 1995. Similarityof Color Images. Proceedings SPIE 2420. SPIE's Symposium on Electronic Imaging: Science and Technology. San Jose, CA, United, March 23.

[6] Rapid Tables.2017. RGB to HSV Color Conversion. (Online) (http://www. rapidtables.com/convert/color/rgb-to-hsv.htm, diakses 19 Agustus 2017)

[7] EEMBC. 2006. RGB to YIQ Conversion. (Online) (https://www.eembc.org/ techlit/datasheets/yiq_consumer.pdf, diakses 19 Agustus 2017)

[8] Schweyer, M. 2015. Color Corversion. (Online) (http://www.equasys. decolorcon version.html, diakses 19 Agustus 2017) 
[9] Shi, Y. Q., Sun, H. 2000. Image and Video Compression for Multimedia Engineering. CRC Press, United States of America

[10] Ford, A., Roberts, A. 1998.Colour Space Conversions. (Online) (http://www. poynton.com/PDFs/coloureq.pdf, di akses 8 September 2017)

[11] Endah, S. N., \& KN, D. M. 2012. Klasifikasi Ucapan Kata dengan Support Vector Machine. Jurnal Masyarakat Informatika, 3(6), 7-14. 